Supporting Information for

\title{
Regulating Polymerization in Graphitic Carbon Nitride to Improve Photocatalytic Activity
}

Jiajie Wu, Xueqiang Ji, Xiaohong Yuan, Ziqiong Zhao, Yueming Li, Bin Wen, Haiquan Zhang,

Dongli Yu, * Yuanchun Zhao, * and Yongjun Tian

State Key Laboratory of Metastable Materials Science and Technology, Yanshan University, Qinhuangdao 066004, China

E-mail: ydl@ysu.edu.cn (D.L.Y); yzhao56@ysu.edu.cn (Y.C.Z.). 


\section{S1. Supplementary Discussion on the Condensation Process}

The thermal condensation from melamine to melon-type g-CN is a typical molecular crystalbased deamination reaction (Figure 1). At $\sim 350{ }^{\circ} \mathrm{C}$, melamine $\left(\mathrm{C}_{3} \mathrm{~N}_{6} \mathrm{H}_{6}\right.$, monoclinic, $P 2_{1} / c$ (No. 14), lattice parameters: $\left.a=7.27 \AA, b=7.48 \AA, c=10.57 \AA, \beta=112.33^{\circ}, Z=4\right)$ will condense into melam $\left(\mathrm{C}_{6} \mathrm{~N}_{11} \mathrm{H}_{9}\right.$, monoclinic, $C 2 / c$ (No. 15), lattice parameters: $a=18.11 \AA$ $\left.=13.98 \AA, \beta=96.31^{\circ}, Z=12\right)::^{\mathrm{S} 1, \mathrm{~S} 2}$

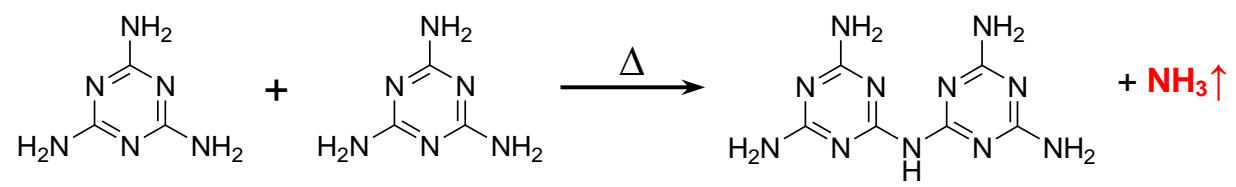

When the temperature increases over $380{ }^{\circ} \mathrm{C}$, melam will condense into melem $\left(\mathrm{C}_{6} \mathrm{~N}_{10} \mathrm{H}_{6}\right.$, monoclinic, $P 2{ }_{1} / c$ (No. 14), lattice parameters: $a=7.40 \AA, b=8.65 \AA, c=13.38 \AA, \beta=99.91^{\circ}, Z$ $=4):{ }^{\mathrm{S} 3}$

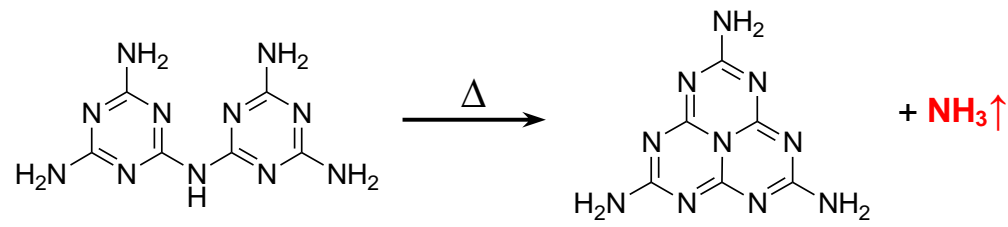

Melem can remain stable from 380 to $500{ }^{\circ} \mathrm{C}$, and thus can be readily synthesized. ${ }^{\mathrm{S}, \mathrm{S} 5}$ When the temperature increases further, it will gradually polymerize into melon-type products (g-CN). Two possible pathways could occur, one is the linear polymerization and the other is carried out in a planar fashion, and the latter is thermodynamically more stable, ultimately generating the ideal heptazine-based $\mathrm{g}-\mathrm{C}_{3} \mathrm{~N}_{4}$ structure. ${ }^{\mathrm{S6,S7}}$ However, in this molecular crystal-based reaction, the polymerizing route could be governed by the specific topochemical environments. Note that the four melem molecules in the unit cell can be divided into two groups that arranged in a "head-to-head" fashion to form hydrogen-bonding networks (Figure 1). Figure S1a shows a $3 \times 4 \times 3$ supercell of the melem structure, suggesting this topochemical polymerization probably 


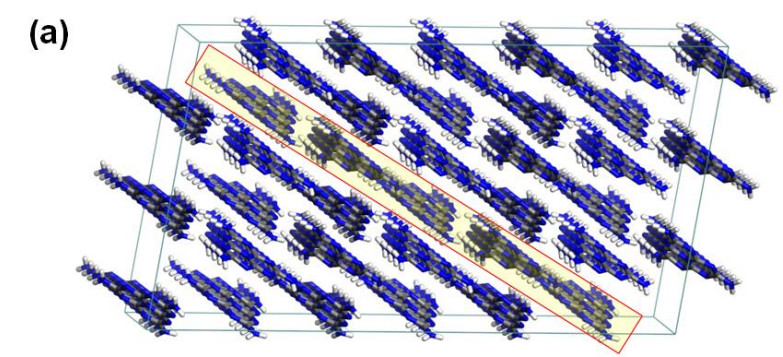

(b)

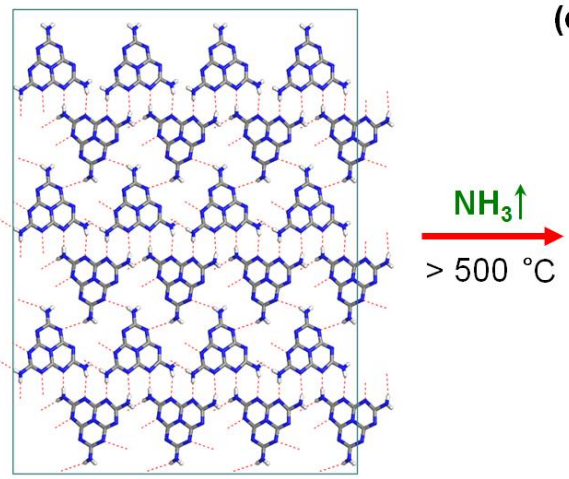

(c)

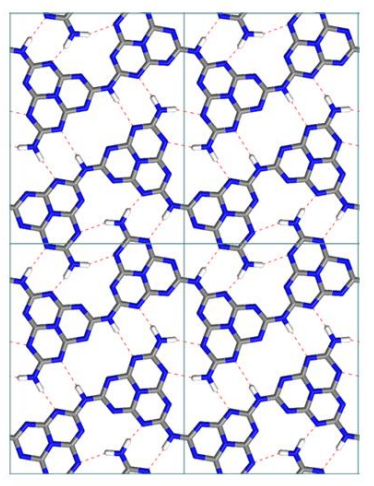

Figure S1. The proposed topochemical polymerization form melem to melon-type g-CN. (a) A $3 \times 4 \times 3$ supercell of melem showing the stacking of (20-2) planes with a stacking distance of 3.45 $\AA$. Top views of the cleaved (b) (20-2) plane of melem structure and (c) (002) plane of an extended $2 \times 2 \times 1$ cell of the orthorhombic melon-type g-CN structure.

would be mainly conducted based on the (20-2) plane with a stacking distance of $3.45 \AA$, in which the arrangement of the molecules shows a good relevance to the zigzag assembling of melon chains in the proposed orthorhombic structure of melon-type g-CN (Figure S1b,c). ${ }^{\mathrm{S} 8, \mathrm{~S} 9}$ This is to say, the topochemical structure of crystalline melem could be kinetically more favorable to facilitate a linear polymerization:<smiles>Cc1ccccc1</smiles><smiles>CC1=NC2=NC(C)=NC3=NC(NC4CCCC4)=NC(=N1)N23</smiles> 


\section{S2. $\mathrm{NH}_{3}$ Concentration in the Quasi-Sealed Reactor}

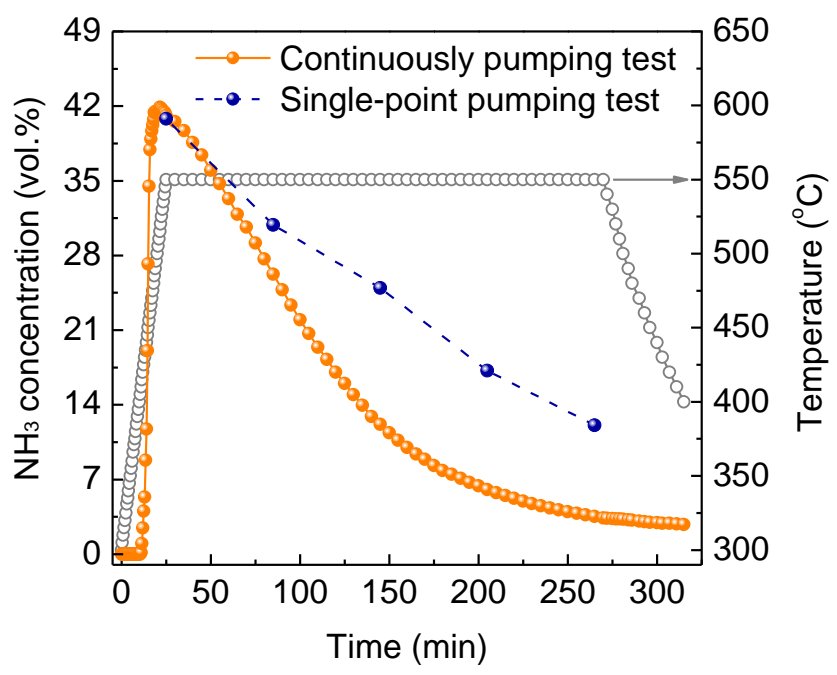

Figure S2. The measured $\mathrm{NH}_{3}$ concentration in the quasi-sealed quartz tube reactor and the corresponding temperature curve for thermal condensation of melon-type g-CN.

In this study, the quasi-sealed condensation route is still in a non-obturating system, in which the diffusion of the $\mathrm{NH}_{3}$ generated during the pre-condensation (from melamine to melem, Reactions (1) and (2) shown in Section S1) will be effectively blocked, producing a rather high $\mathrm{NH}_{3}$ concentration. The $\mathrm{NH}_{3}$ concentration in the quasi-sealed reactor during thermal condensation was directly measured by using a full-range $\mathrm{NH}_{3}$ analyzer $\left(\mathrm{RQS6}-\mathrm{NH}_{3}\right.$, Suzhou Runqi, China) equipped with a built-in pump and a thermalconductivity detector (system error: $\leq$ $\pm 2 \%$ F.S). As shown in Figure S2, for a continuously pumping test, the $\mathrm{NH}_{3}$ concentration reaches its maximum of $41.90 \mathrm{vol} . \%$ at $515{ }^{\circ} \mathrm{C}$ and then decreases gradually. We have also carried out single-point pumping measurements for five independent runs of thermal condensation, and found that the $\mathrm{NH}_{3}$ concentration was still as high as 12.09 vol.\% in the end of thermal condensation (4 hour) at $550{ }^{\circ} \mathrm{C}$. The $\mathrm{NH}_{3}$ concentration in the quasi-sealed reactor will 
remarkably affect the polymerization reaction kinetics, and prohibit the formation of high-DP components, producing melon-type g-CN with a narrower and uniform DP distribution.

\section{S3. Supplementary Results and Discussion}

Table S1. Comparison of the Detected (002) Diffraction Peaks of $\mathrm{CN}_{-} \mathrm{N}_{2}, \mathrm{CN}-\mathrm{Air}$, and CNOpt

\begin{tabular}{cccc}
\hline samples & $2 \theta\left({ }^{\circ}\right)$ & $d_{(002)}(\AA)$ & FWHM $\left(^{\circ}\right)$ \\
\hline CN-N 2 & 27.5 & 3.24 & 1.04 \\
CN-Air & 27.3 & 3.27 & 1.51 \\
CN-Opt & 27.8 & 3.21 & 0.91 \\
\hline
\end{tabular}

The interplanar stacking order of the synthesized g-CN samples has been evaluated by comparing the position and the full width at half-maximum (FWHM) of the detected (002) diffraction peaks. As shown in Table S1, the stacking distance $\left(d_{(002)}\right)$ of $\mathrm{CN}-\mathrm{Opt}$ is calculated to be $3.21 \AA$ with a FWHM of $0.91^{\circ}$, both of them are smaller than those of $\mathrm{CN}-\mathrm{N}_{2}$ and $\mathrm{CN}-\mathrm{Air}$, clearly demonstrating its improved crystallinity. Moreover, due to the oxygen-induced thermal etching, CN-Air exhibits a worse interplanar stacking order than that of $\mathrm{CN}-\mathrm{N}_{2}$. 


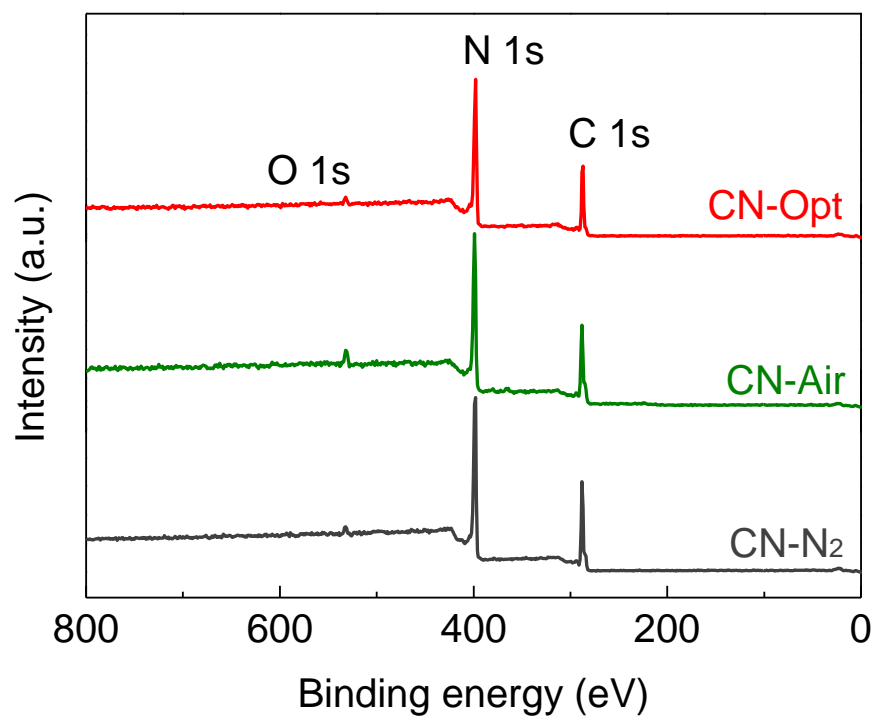

Figure S3. XPS survey spectra of $\mathrm{CN}_{-}-\mathrm{N}_{2}, \mathrm{CN}-\mathrm{Air}$, and $\mathrm{CN}-\mathrm{Opt}$, showing the synthesized samples only contain contain $\mathrm{C}, \mathrm{N}$, and $\mathrm{O}$ elements.

Table S2. Relative Integrated Contents of Each Bonding State Determined in the Deconvoluted C 1s and N 1s XPS Spectra of CN-N, CN-Air, and CN-Opt, Respectively

\begin{tabular}{|c|c|c|c|c|c|c|c|}
\hline \multirow{2}{*}{ samples } & \multicolumn{3}{|c|}{$\mathrm{C} 1 \mathrm{~s}$} & \multicolumn{4}{|c|}{$\mathrm{N} 1 \mathrm{~s}$} \\
\hline & $\begin{array}{c}\mathrm{C}_{\mathrm{ad}}(\%) \\
(284.6 \mathrm{eV})\end{array}$ & $\begin{array}{c}\mathrm{C}_{3 \mathrm{~N}}(\%) \\
(287.9 \mathrm{eV})\end{array}$ & $\begin{array}{c}\mathrm{C}_{\mathrm{C}-\mathrm{O}}(\%) \\
(289.0 \mathrm{eV})\end{array}$ & $\begin{array}{c}\mathrm{N}_{2 \mathrm{C}}(\%) \\
(398.3 \mathrm{eV})\end{array}$ & $\begin{array}{c}\mathrm{N}_{3 \mathrm{C}}(\%) \\
(399.7 \mathrm{eV})\end{array}$ & $\begin{array}{c}\mathrm{N}_{\mathrm{N}-\mathrm{H}}(\%) \\
(400.8 \mathrm{eV})\end{array}$ & $\mathrm{N}_{\mathrm{N}-\mathrm{H}} / \mathrm{N}_{3 \mathrm{C}}$ \\
\hline $\mathrm{CN}-\mathrm{N}_{2}$ & 12.8 & 85.6 & 1.6 & 77.1 & 14.0 & 8.9 & 0.64 \\
\hline $\mathrm{CN}$-Air & 19.0 & 73.8 & 7.2 & 78.4 & 14.9 & 6.7 & 0.45 \\
\hline $\mathrm{CN}-\mathrm{Opt}$ & 16.5 & 79.9 & 3.6 & 74.1 & 13.2 & 12.7 & 0.96 \\
\hline
\end{tabular}




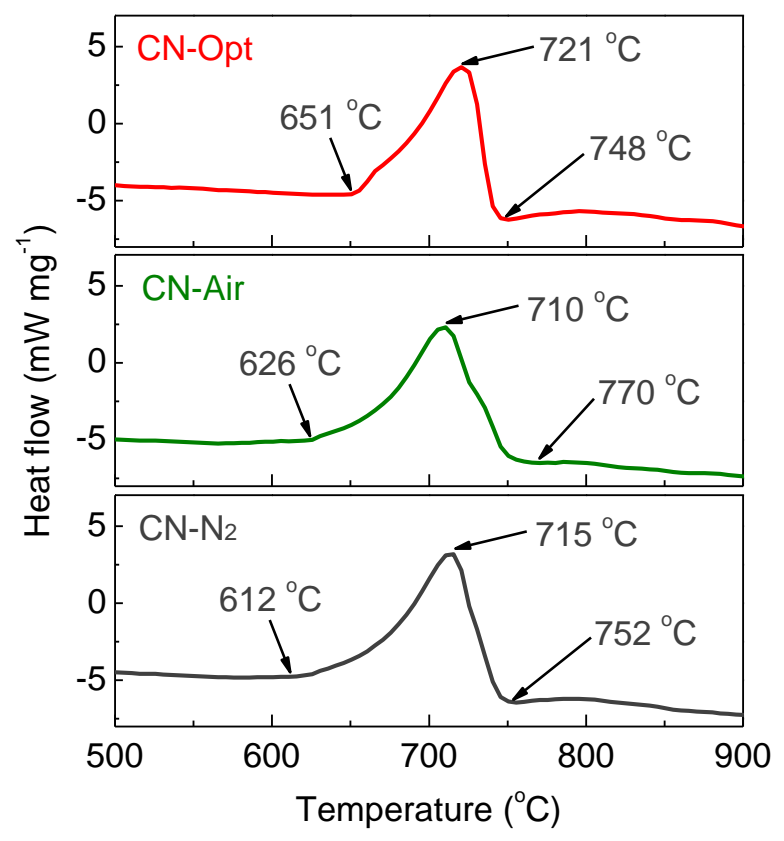

Figure S4. Detailed analyses of the DSC curves of $\mathrm{CN}_{-} \mathrm{N}_{2}, \mathrm{CN}-\mathrm{Air}$, and $\mathrm{CN}-\mathrm{Opt}$, respectively.

Detailed analyses shown in Figure S4 indicate that the maximum of the DSC peaks are located at $715{ }^{\circ} \mathrm{C}$ for $\mathrm{CN}-\mathrm{N}_{2}, 710{ }^{\circ} \mathrm{C}$ for $\mathrm{CN}$-Air, and $721{ }^{\circ} \mathrm{C}$ for $\mathrm{CN}$-Opt, respectively; which are well related to the crystallinity of the samples. Compared to that of CN-Opt, both the DSC peaks of $\mathrm{CN}-\mathrm{N}_{2}$ and $\mathrm{CN}$-Air are obviously broader. The extension toward low-temperature region corresponds to the decomposition of the low-DP components in the samples, while those with relatively higher DPs in the samples lead to a slower decomposition under higher temperatures. 


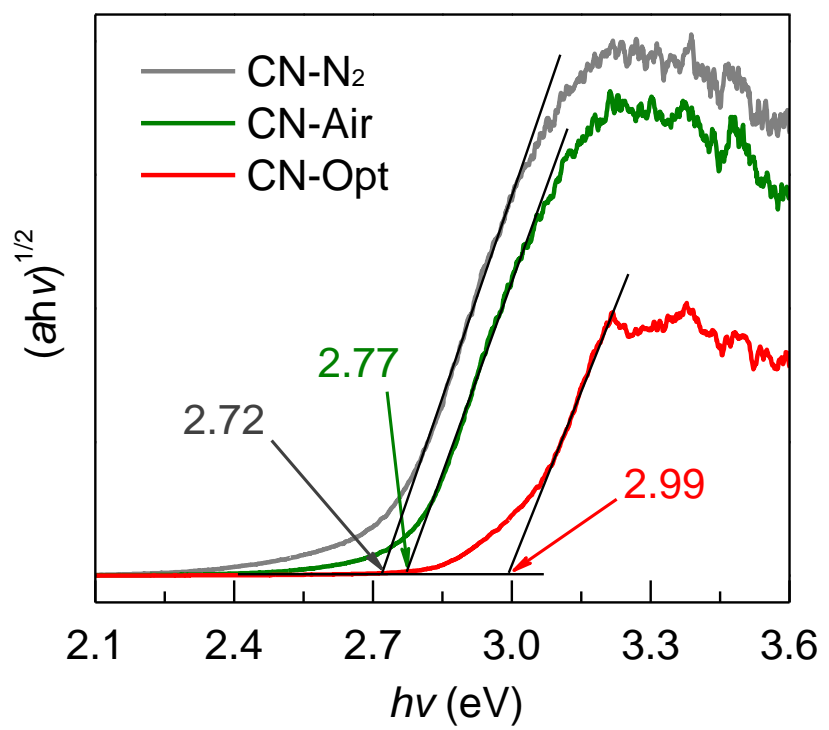

Figure S5. Corresponding Tauc plots of the measured UV-vis diffuse reflectance spectra, and the derived band gaps are $2.72 \mathrm{eV}$ for $\mathrm{CN}_{-} \mathrm{N}_{2}, 2.77 \mathrm{eV}$ for $\mathrm{CN}-\mathrm{Air}$, and $2.99 \mathrm{eV}$ for $\mathrm{CN}-\mathrm{Opt}$, respectively.

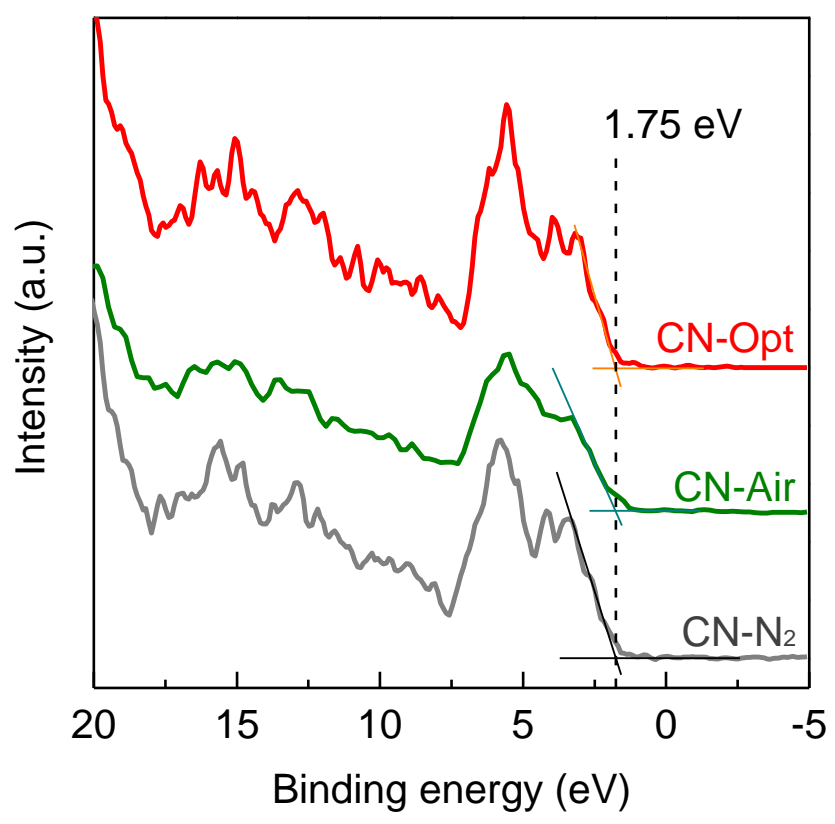

Figure S6. XPS valence band spectra of $\mathrm{CN}-\mathrm{N}_{2}, \mathrm{CN}-\mathrm{Air}$, and $\mathrm{CN}-\mathrm{Opt}$. 


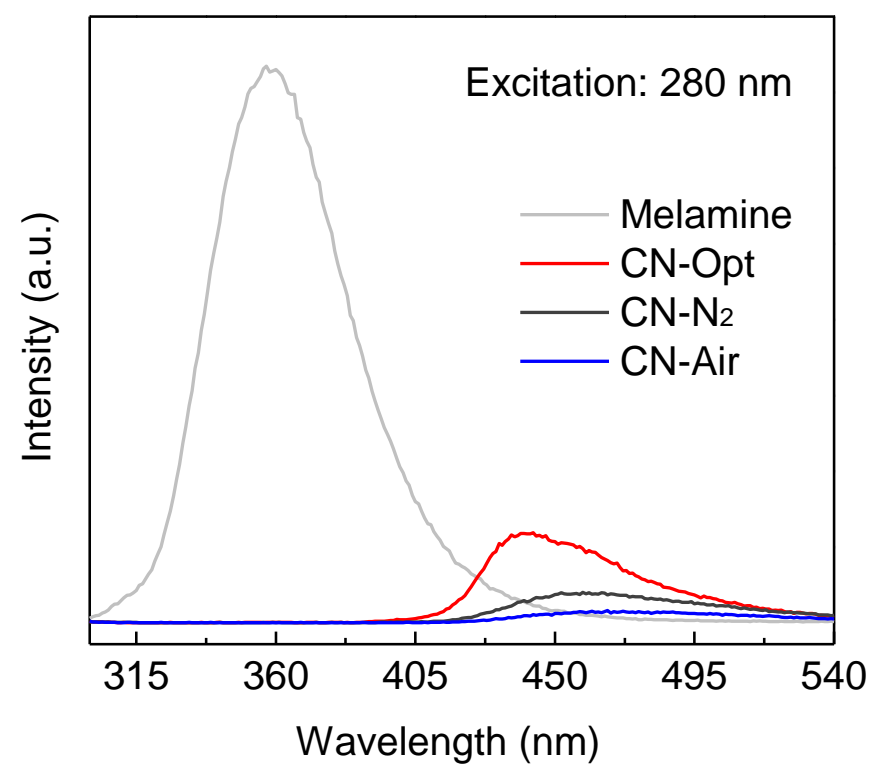

Figure S7. PL spectra of the synthesized samples and melamine under an excitation at $280 \mathrm{~nm}$. After thermal condensation, all the PL emissions of the g-CN samples show redshifts with remarkably decreased PL intensities. 

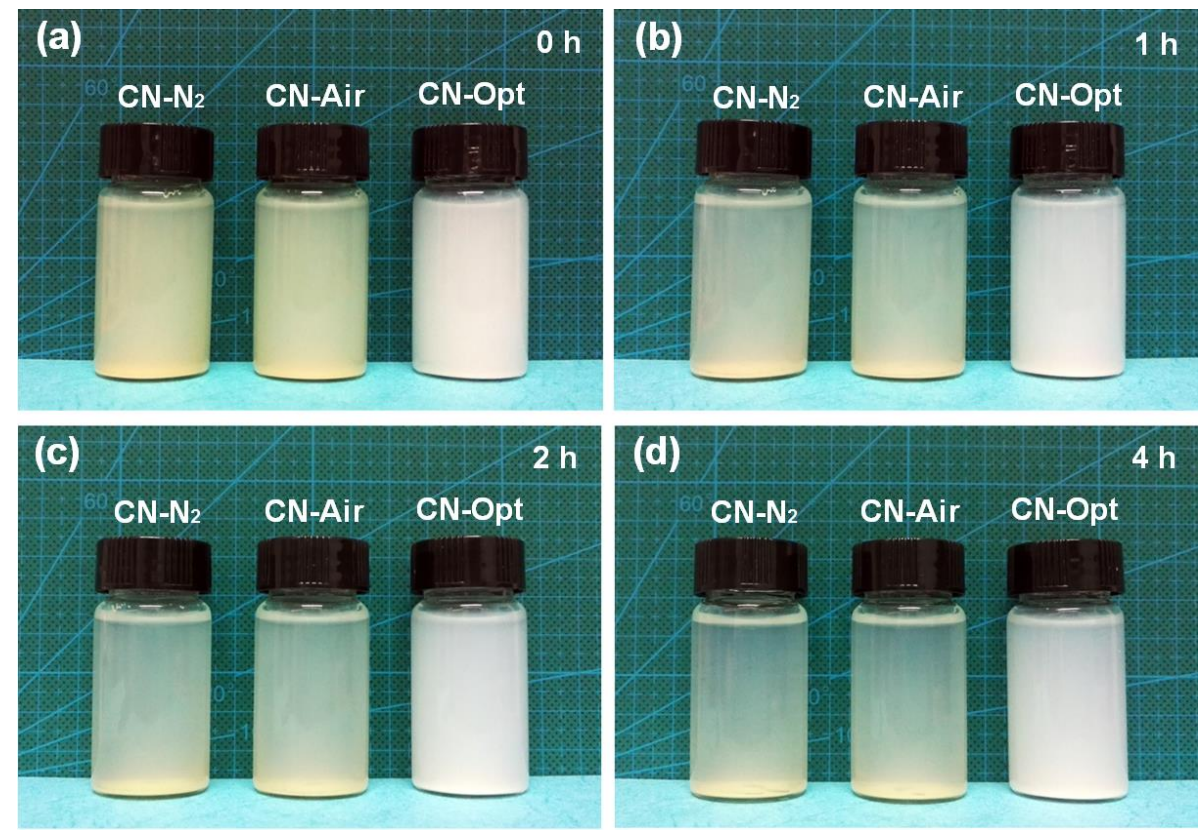

Figure S8. Water dispersibility of the synthesized samples after being kept for (a) $0 \mathrm{~h}$, (b) $1 \mathrm{~h}$, (c) $2 \mathrm{~h}$, and (d) $4 \mathrm{~h}$, respectively.

In order to test the water dispersibility of the synthesized samples, $10 \mathrm{mg}$ sample powders were dispersed in $20 \mathrm{~mL}$ deionized water by bath sonication; and then the obtained suspensions were kept statically for observation. After being kept for $4 \mathrm{~h}, \sim 18 \mathrm{~mL}$ supernatant of each suspension was carefully withdrawn. The concentration of the obtained supernatant was calculated by the following equation:

$$
c=\frac{10-W_{\text {residual }}}{W_{\text {supernatant }}} \times 100 \%
$$

The residual sample (suspension) was thoroughly dried in an oven at $200{ }^{\circ} \mathrm{C}$ to measure its weight ( $W_{\text {residual }}, \mathrm{mg}$ ). The obtained supernatants were further diluted into different concentrations to perform dynamic light scattering and zeta potential measurements. 

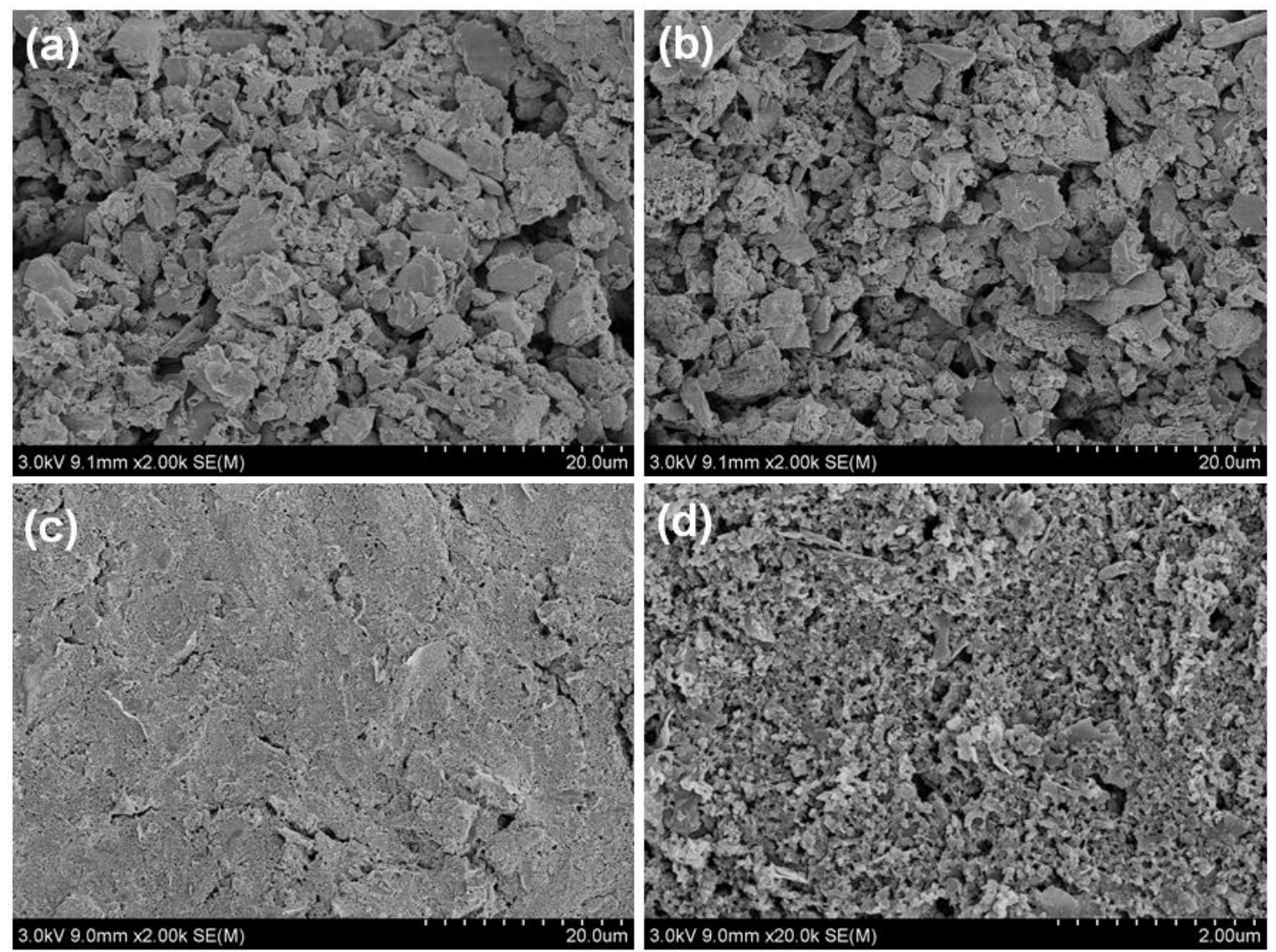

(e)

(f)
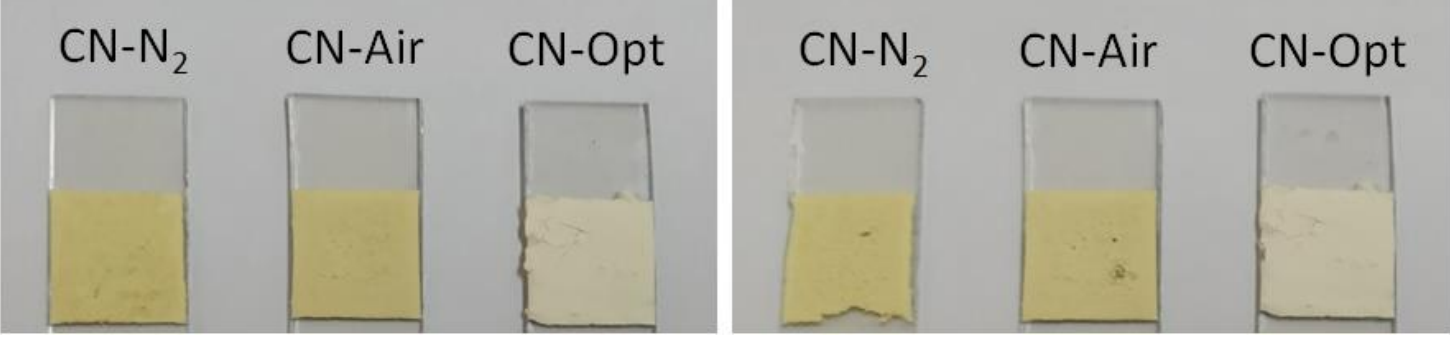

Figure S9. SEM images of (a) $\mathrm{CN}_{-} \mathrm{N}_{2}$, (b) $\mathrm{CN}$-Air, and (c) $\mathrm{CN}-\mathrm{Opt}$ photoelectrodes. (d) A highmagnification SEM image showing the nanoporous texture of CN-Opt photoelectrode. Optical images of the fabricated photoelectrodes (e) before and (f) after photoelectrochemical measurements, respectively. 


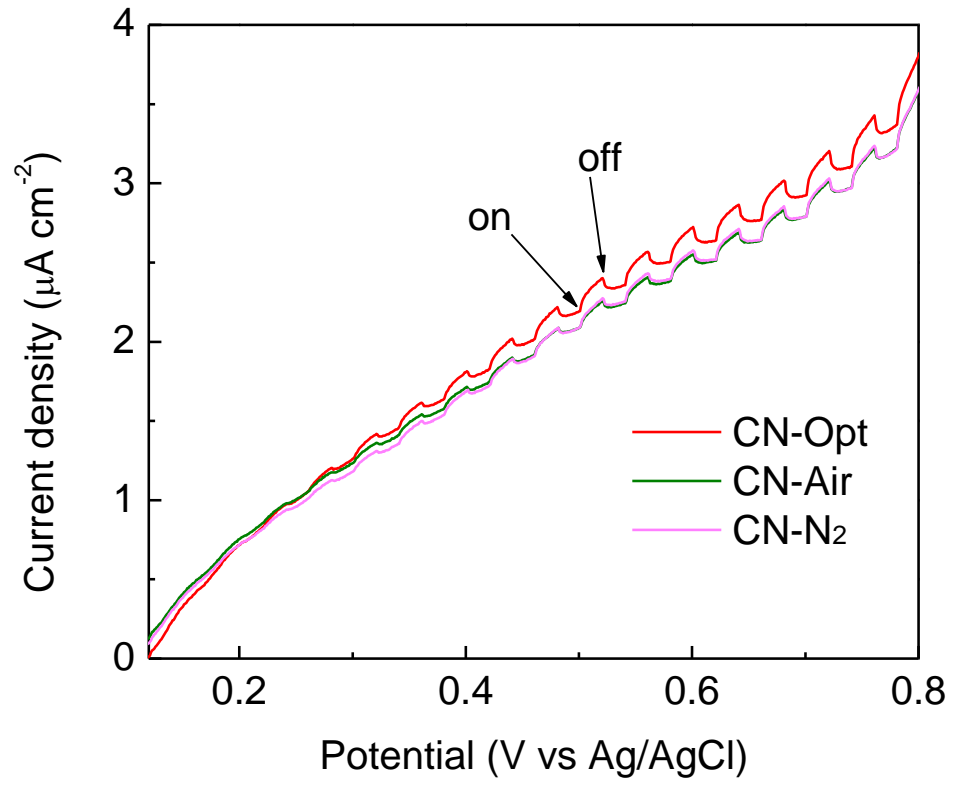

Figure S10. Photocurrent responses with linear sweep voltammetry (LSV) measurements in a $0.5 \mathrm{M} \mathrm{Na}_{2} \mathrm{SO}_{4}$ electrolyte under an irradiation of chopped visible light $(\lambda>420 \mathrm{~nm})$. The potential sweep rate is $1 \mathrm{mV} \mathrm{s}^{-1}$. Notable photocurrents can be detected when the biased potential is larger than $0.2 \mathrm{~V}$ vs $\mathrm{Ag} / \mathrm{AgCl}$ for the $\mathrm{g}-\mathrm{CN}$ samples. 

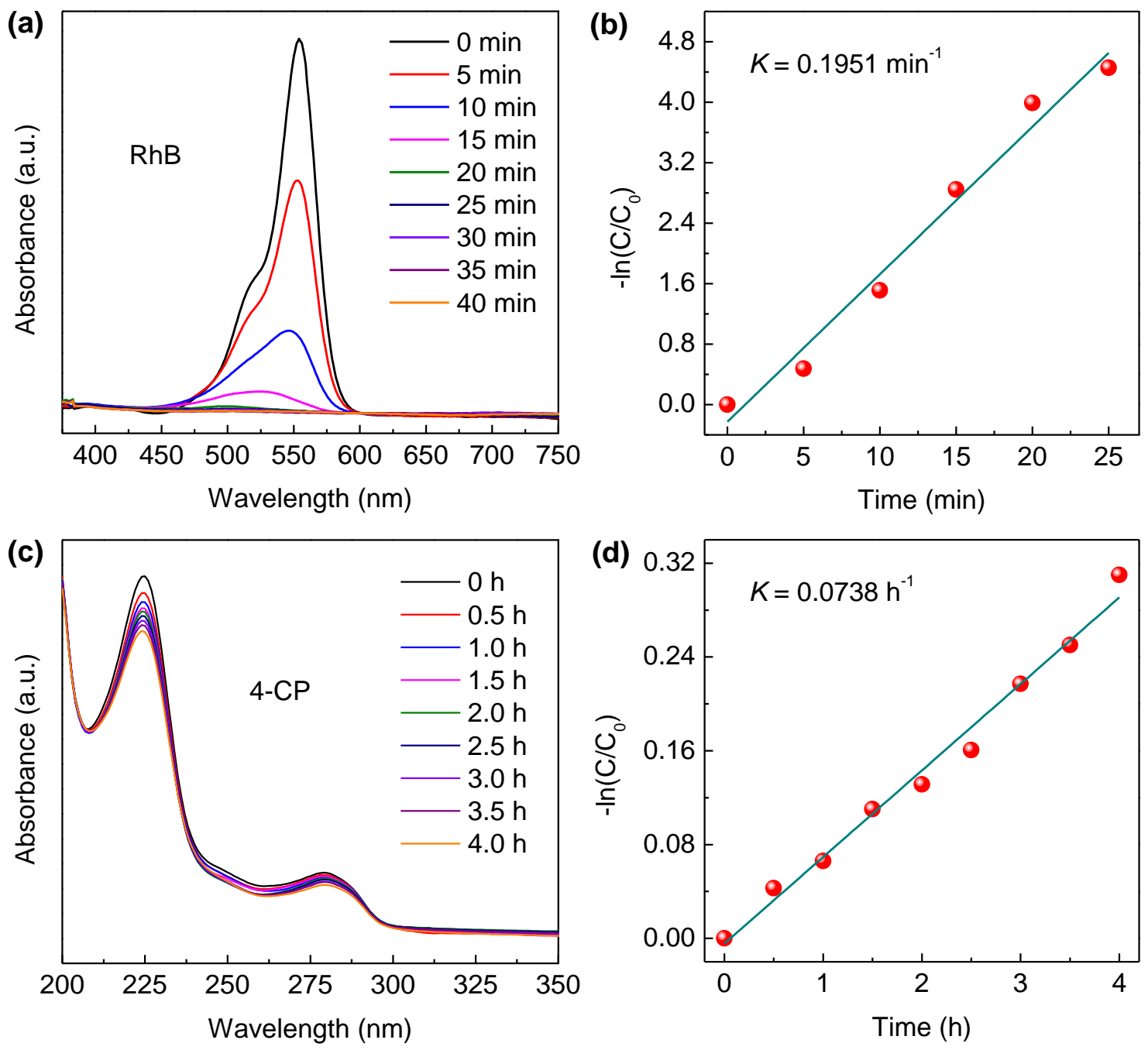

Figure S11. Typical time-dependent UV-vis absorption spectra and the corresponding first-order kinetic plots for photodegradation of $(\mathrm{a}, \mathrm{b}) \mathrm{RhB}$ and $(\mathrm{c}, \mathrm{d})$ 4-CP catalysed by $\mathrm{CN}-\mathrm{Opt}$ under visible light irradiation $(\lambda>420 \mathrm{~nm})$, respectively. 

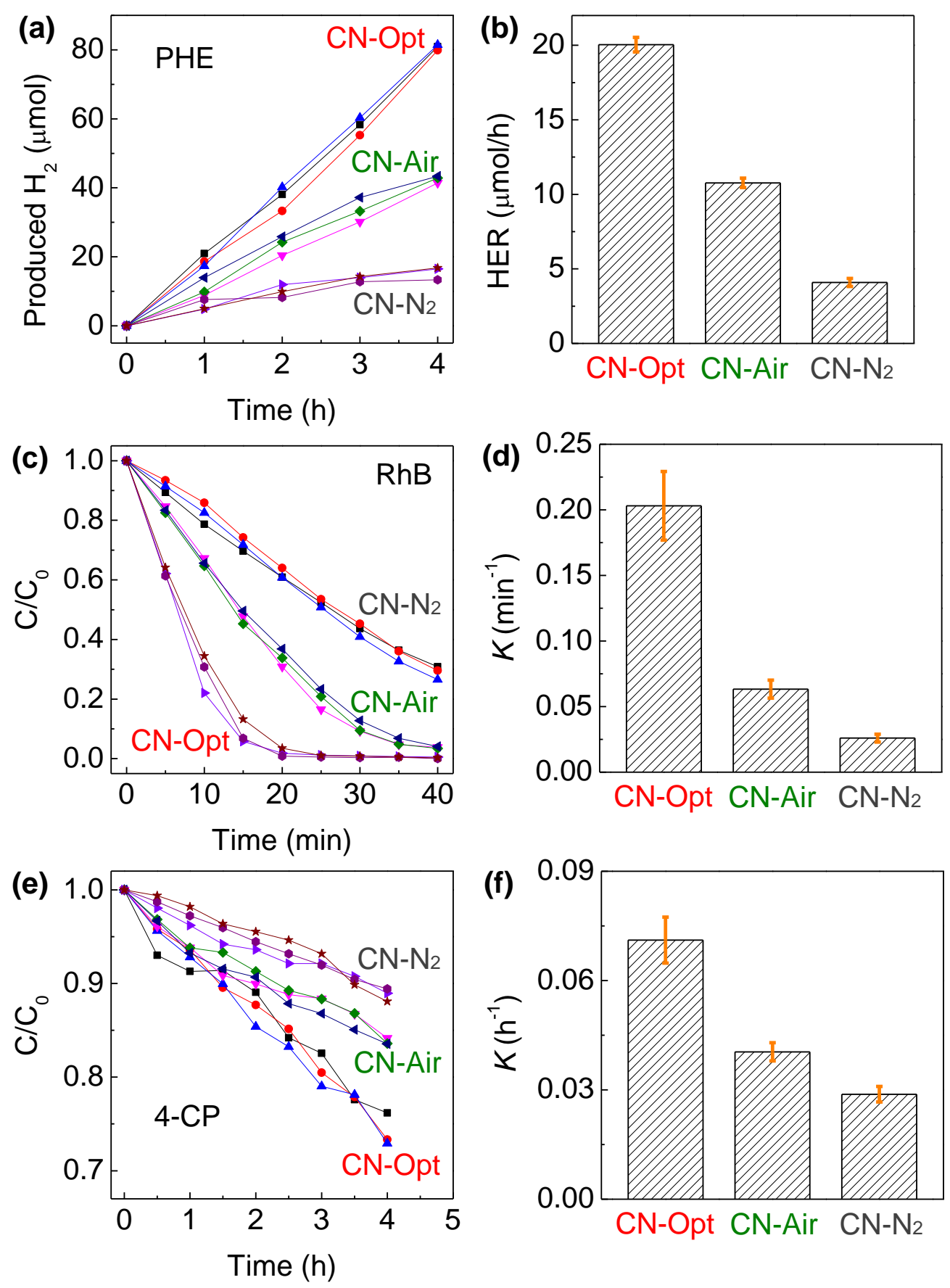

Figure S12. Raw data of the visible-light photocatalytic activity measurements $(\lambda>420 \mathrm{~nm})$. (a) Photocatalytic hydrogen evolution and (b) the corresponding hydrogen evolution rate (HER). Photodegradation processes and the corresponding first-order degradation constant $(K)$ for $(\mathrm{c}, \mathrm{d})$ $\mathrm{RhB}$ and (e,f) 4-CP, respectively. 


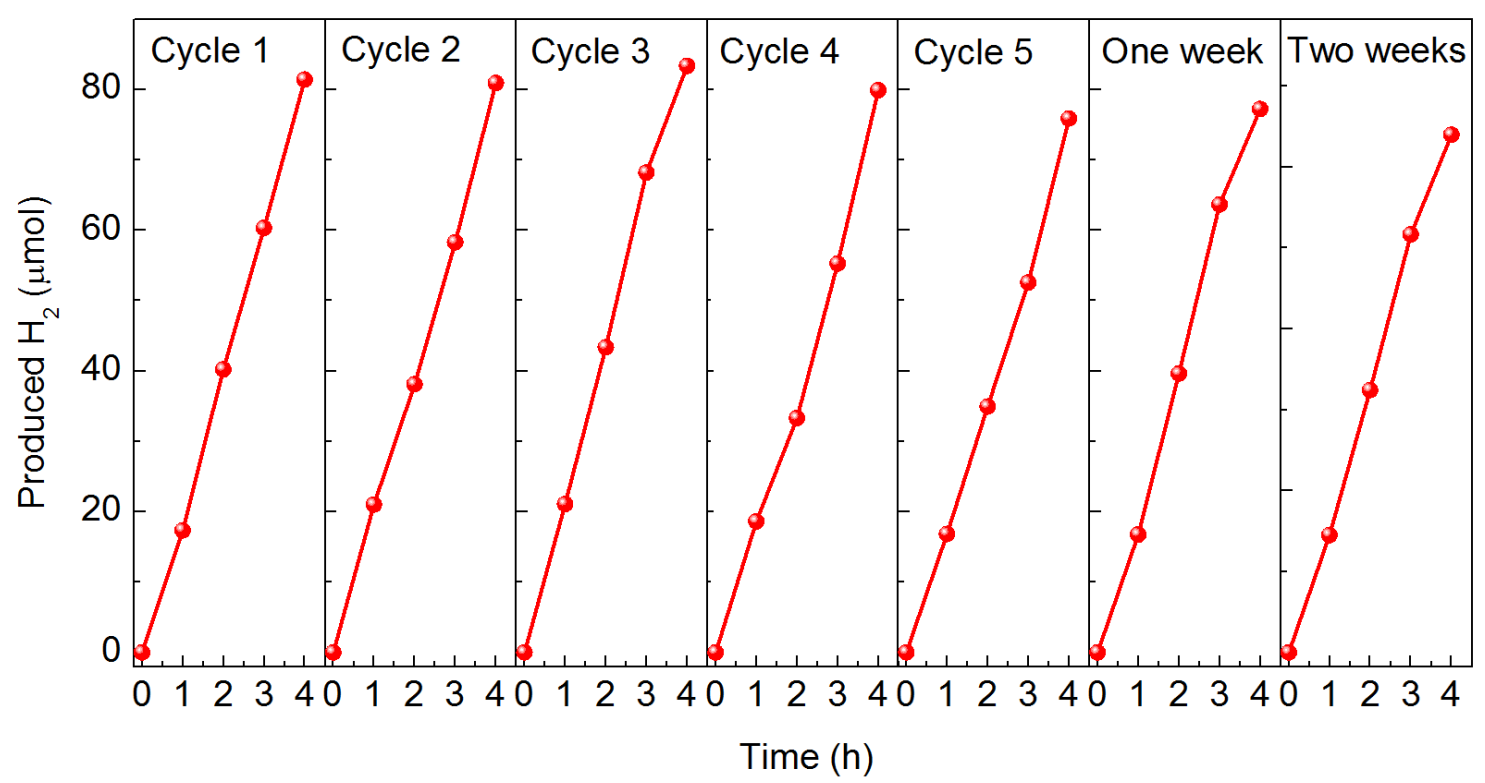

Figure S13. Stability of the photocatalytic hydrogen evolution performance of CN-Opt under visible light irradiation $(\lambda>420 \mathrm{~nm})$.

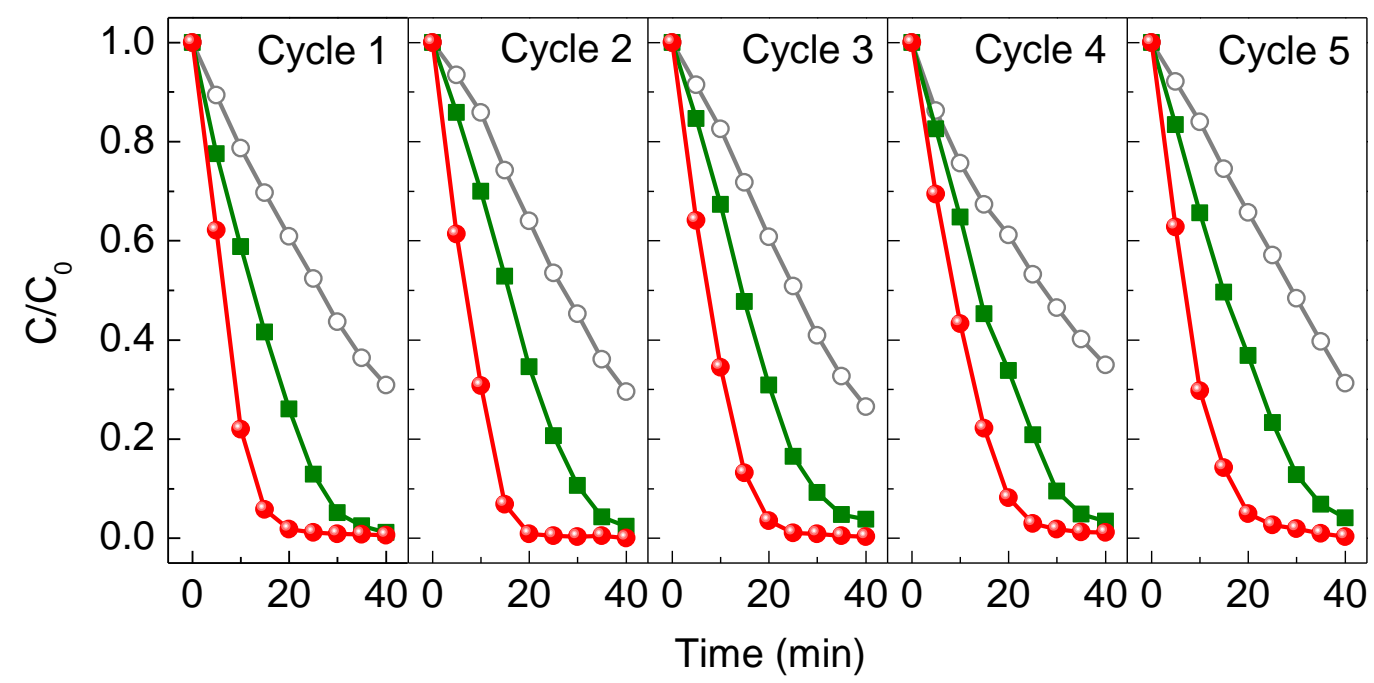

Figure S14. Stability of the photocatalytic activities of $\mathrm{CN}-\mathrm{N}_{2}$ (grey circle-lines), $\mathrm{CN}$-Air (olive square-lines), and $\mathrm{CN}$-Opt (red dot-lines) for degradation of $\mathrm{RhB}$ under visible light irradiation $(\lambda>420 \mathrm{~nm})$. 


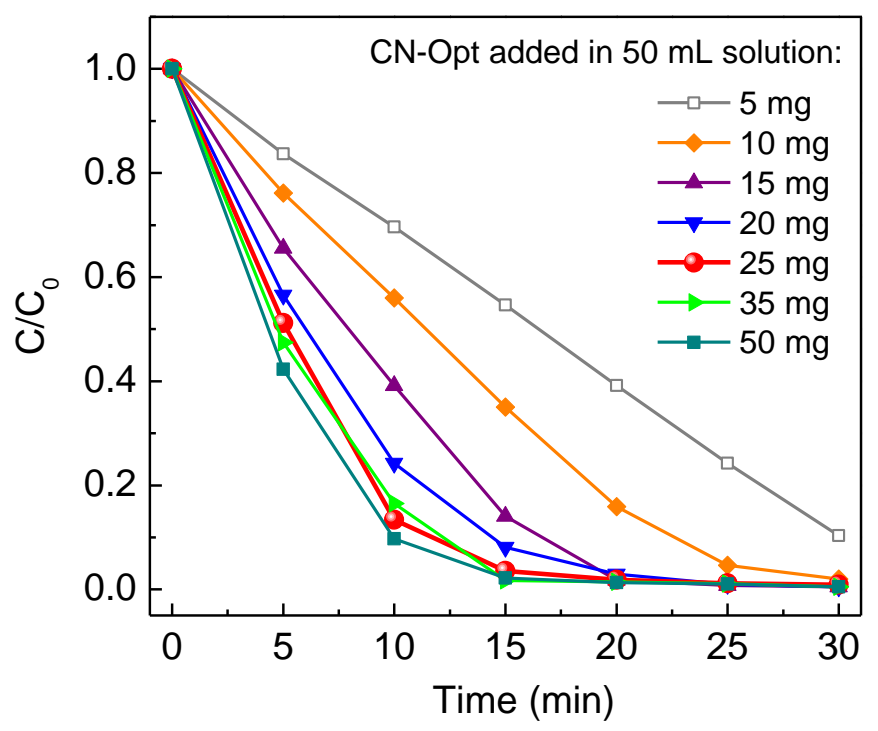

Figure S15. Degradation performance of RhB by adding different amounts of CN-Opt catalyst into $50 \mathrm{~mL} \mathrm{RhB}$ solution $\left(2 \times 10^{-5} \mathrm{M}\right)$ under visible light irradiation $(\lambda>420 \mathrm{~nm})$. 

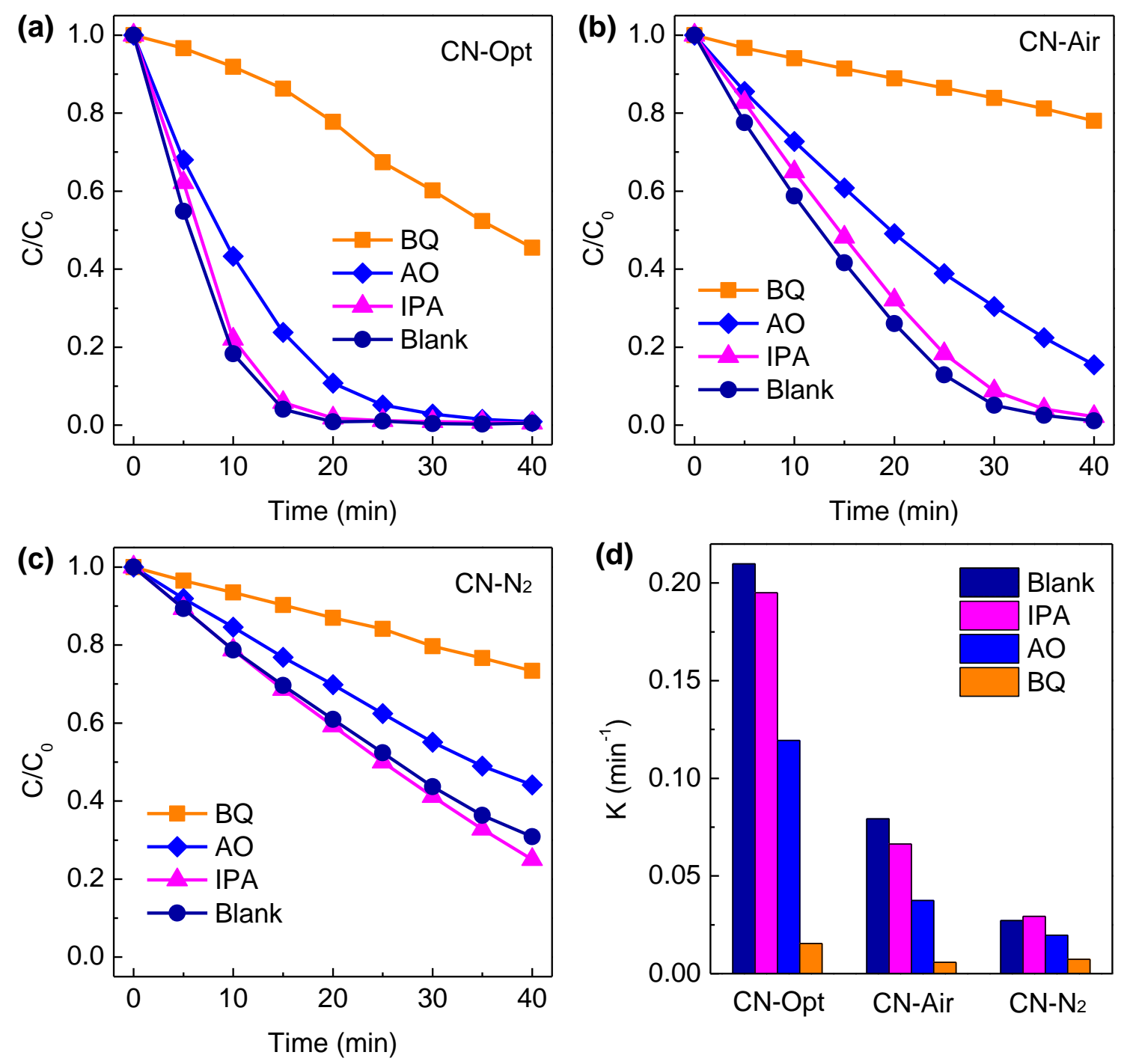

Figure S16. Trapping experiments for the photodegradation of $\mathrm{RhB}$ without (blank) or with different scavengers catalysed by (a) $\mathrm{CN}-\mathrm{Opt}$, (b) $\mathrm{CN}-\mathrm{Air}$, and (c) $\mathrm{CN}-\mathrm{N}_{2}$ under visible light irradiation $(\lambda>420 \mathrm{~nm})$. The employed scavengers are isopropyl alcohol (IPA) for hydroxyl radicals, ammonium oxalate ( $\mathrm{AO})$ for photogenerated holes, and p-benzoquinone (BQ) for superoxide radicals, respectively. The concentration of the scavengers is $1 \mathrm{mM}$ for all the degradation tests. (d) Comparison of the corresponding first-order degradation constants. 

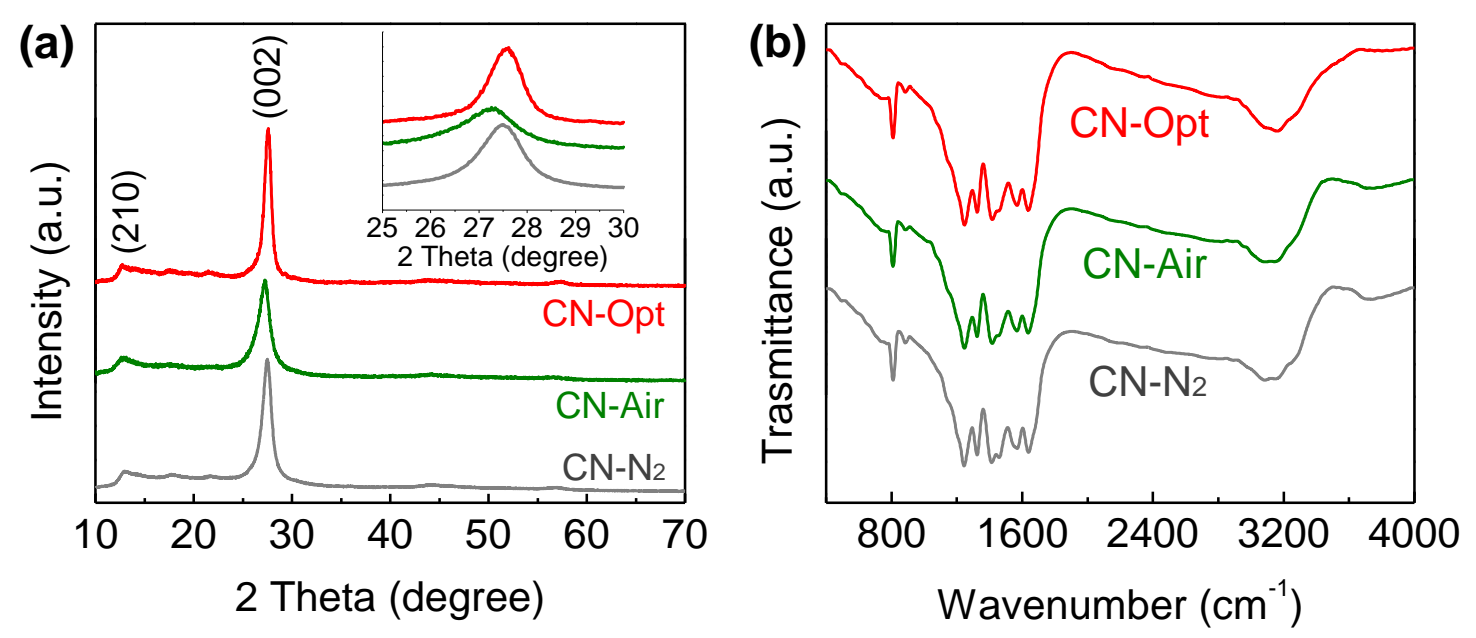

Figure S17. (a) XRD patterns and (b) FTIR spectra of the g-CN catalysts after the recycled RhB degradation tests. The photocatalyst powders were re-collected by centrifugation, carefully washed by de-ionized water for several times, and then dried in an oven at $200{ }^{\circ} \mathrm{C}$ overnight. 

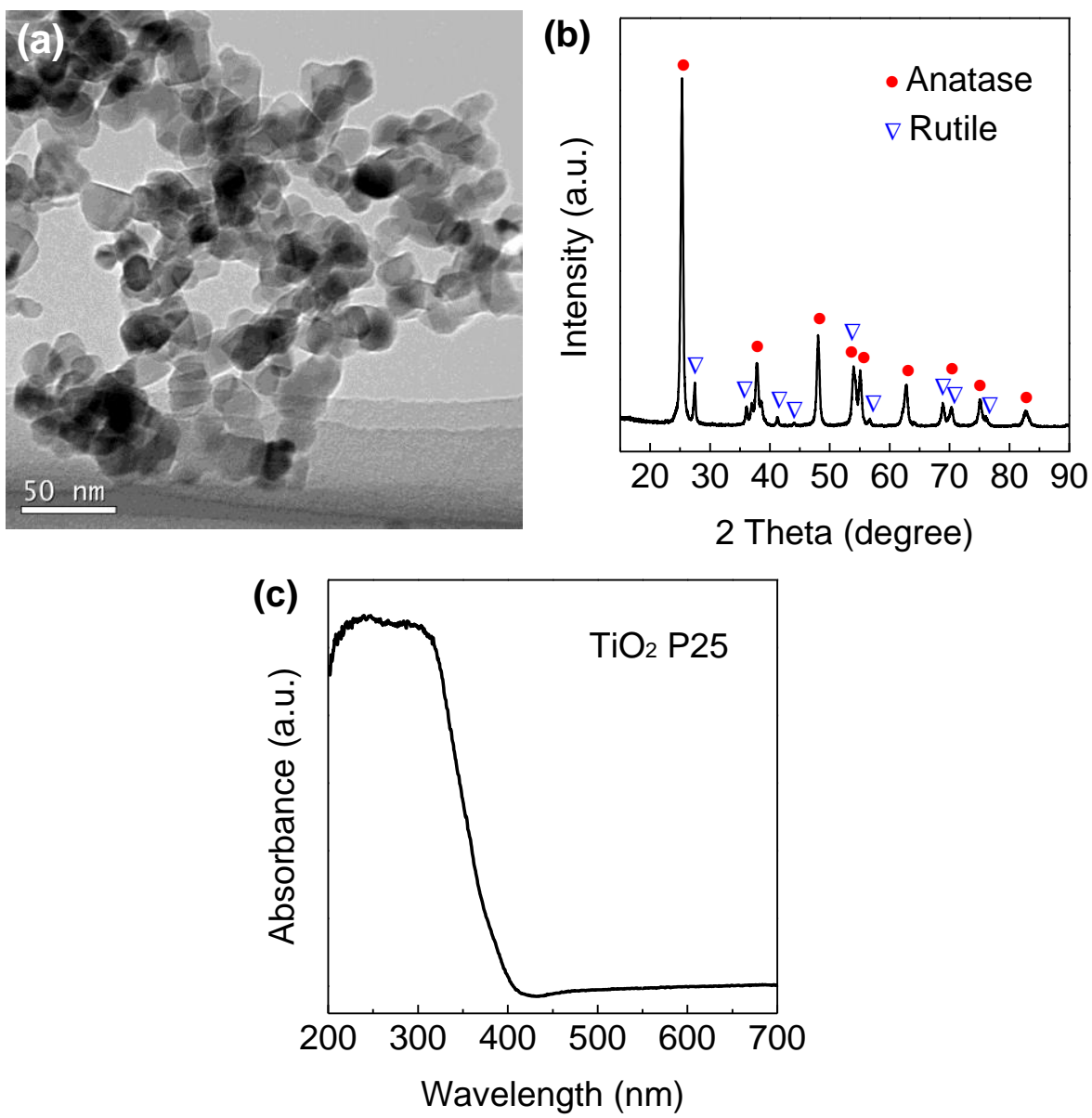

Figure S18. (a) TEM image, (b) XRD pattern showing the mixed anatase and rutile phases, and (c) UV-vis diffuse reflectance spectrum of Degussa $\mathrm{TiO}_{2} \mathrm{P} 25$.

Degussa $\mathrm{TiO}_{2} \mathrm{P} 25$ was purchased from Evonik Industries AG without further treatment, which has been widely used as a representative oxide photocatalyst with excellent activities. The catalyst is of an average particle size of $\sim 21 \mathrm{~nm}$ and composed of about $79 \%$ anatase phase and $21 \%$ rutile phase, respectively. The reported specific surface area (BET) is about $50 \mathrm{~m}^{2} \mathrm{~g}^{-1}$. 

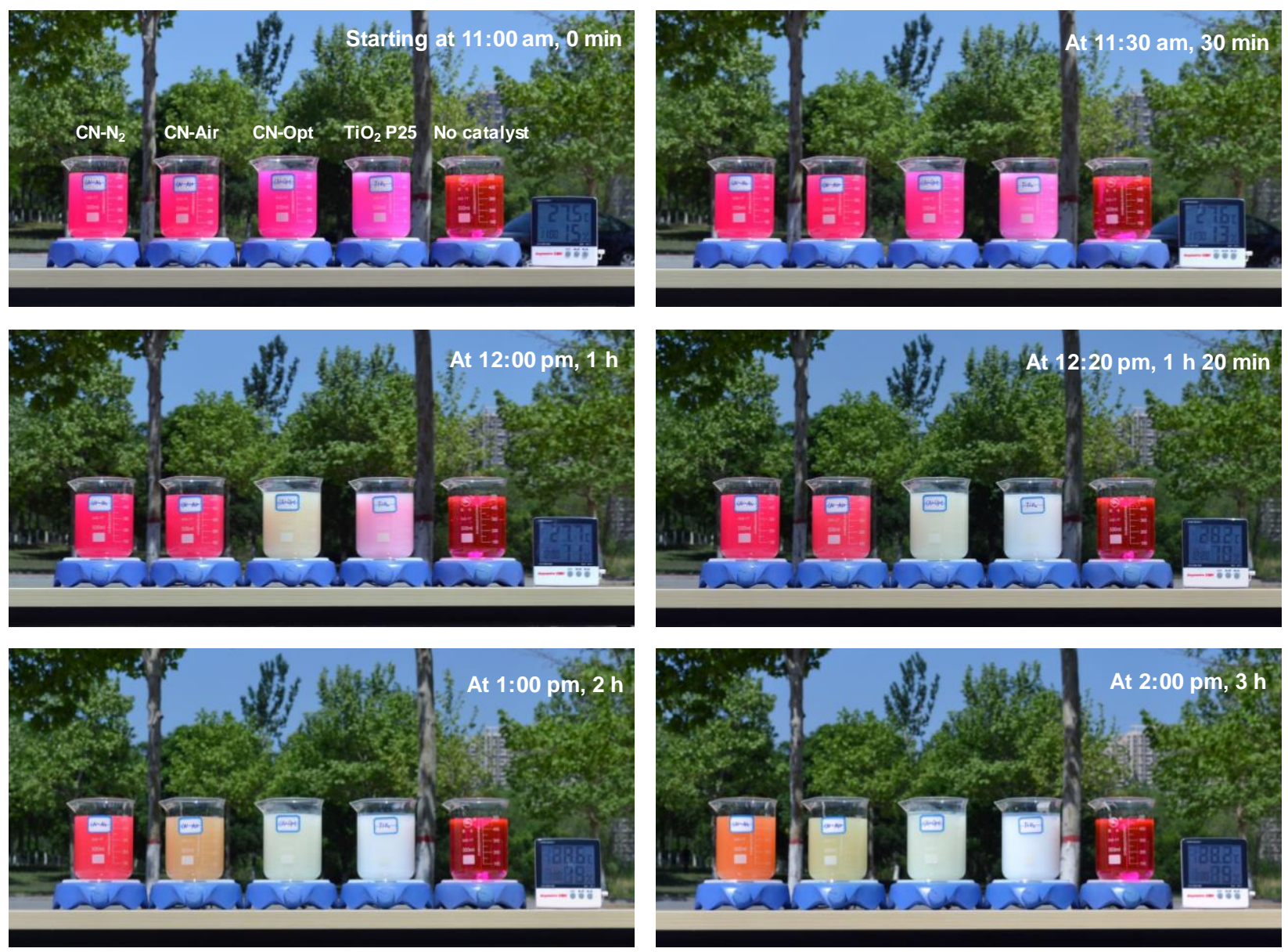

Figure S19. Scale-up demonstration of the degradation process of $\mathrm{RhB}\left(500 \mathrm{~mL}, 2 \times 10^{-5} \mathrm{M}\right)$ catalysed by $\mathrm{CN}-\mathrm{N}_{2}, \mathrm{CN}-\mathrm{Air}, \mathrm{CN}-\mathrm{Opt}$, and Degussa $\mathrm{TiO}_{2} \mathrm{P} 25$ under natural sunlight irradiation (location: latitude $39^{\circ} 54^{\prime}$ North, and longitude $119^{\circ} 31^{\prime}$ East). 

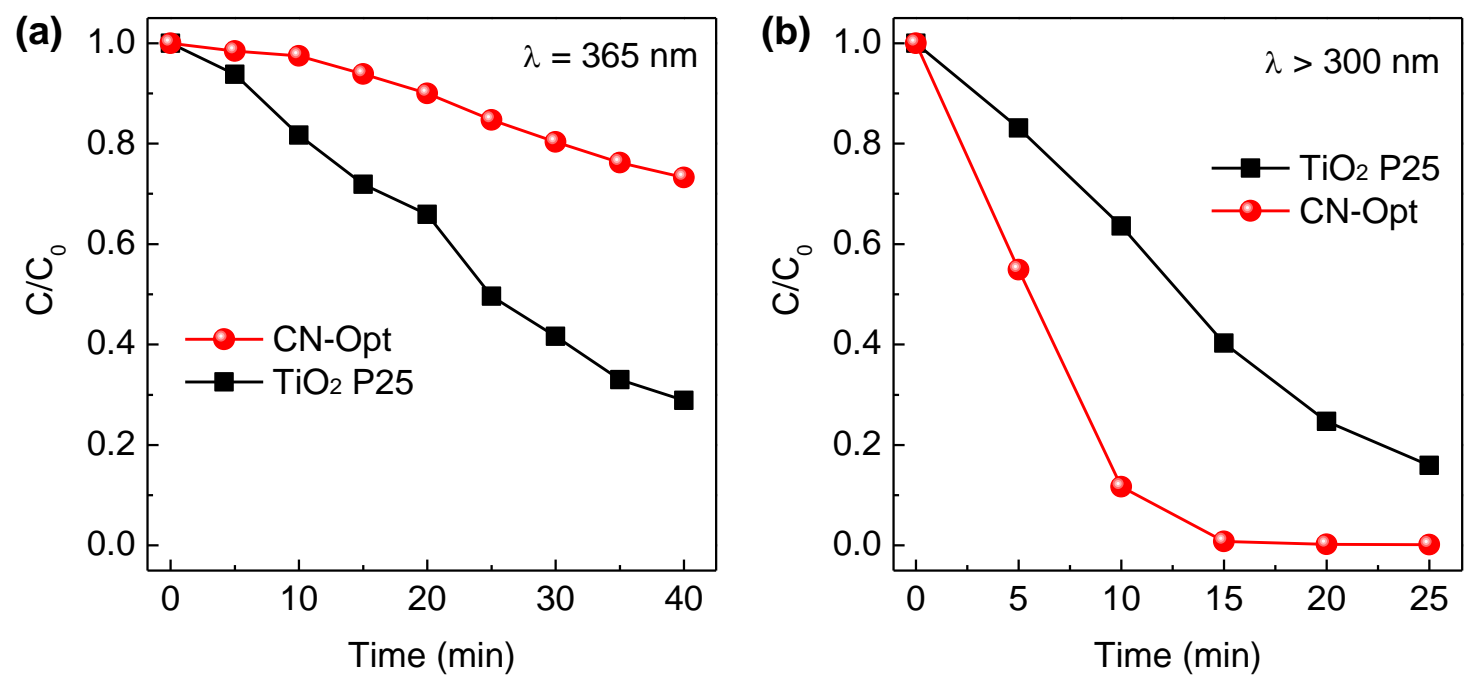

Figure S20. Photocatalytic activities of CN-Opt and Degussa $\mathrm{TiO}_{2} \mathrm{P} 25$ evaluated by degradation of $\mathrm{RhB}$ under irradiation of (a) a $365 \mathrm{~nm}$ UV light (FWHM: $15 \mathrm{~nm}$ ) and (b) the Xe lamp equipped with a full spectral aluminium reflector $(\lambda>300 \mathrm{~nm})$. 


\section{S4. References}

(S1) Lotsch, B. V.; Schnick, W. New Light on an Old Story: Formation of Melam during Thermal Condensation of Melamine. Chem. - Eur. J. 2007, 13, 4956-4968.

(S2) Yuan, X.; Luo, K.; Liu, N.; Ji, X.; Liu, C.; He, J.; Tian, G.; Zhao, Y.; Yu, D. ClusterModel DFT Simulations of the Infrared Spectra of Triazine-Based Molecular Crystals. Phys. Chem. Chem. Phys. 2018, 20, 20779-20784.

(S3) Jürgens, B.; Irran, E.; Senker, J.; Kroll, P.; Muiller, H.; Schnick, W. Melem (2,5,8Triamino-tri-s-triazine), an Important Intermediate during Condensation of Melamine Rings to Graphitic Carbon Nitride: Synthesis, Structure Determination by X-ray Powder Diffractometry, Solid-State NMR, and Theoretical Studies. J. Am. Chem. Soc. 2003, 125, 10288-10300.

(S4) Chu, S.; Wang, C.; Feng, J.; Wang, Y.; Zou, Z. Melem: A Metal-Free Unit for Photocatalytic Hydrogen Evolution. Int. J. Hydrogen Energy 2014, 39, 13519-13526.

(S5) Zheng, H. B.; Chen, W.; Gao, H.; Wang, Y. Y.; Guo, H. Y.; Guo, S. Q.; Tang, Z. L.; Zhang, J. Y. Melem: An Efficient Metal-Free Luminescent Material. J. Mater. Chem. C, 2017, 5, 10746-10753.

(S6) Gracia, J.; Kroll, P. Corrugated Layered Heptazine-Based Carbon Nitride: the Lowest Energy Modifications of $\mathrm{C}_{3} \mathrm{~N}_{4}$ Ground State. J. Mater. Chem. 2009, 19, 3013-3019.

(S7) Ma, X.; Lv, Y.; Xu, J.; Liu, Y.; Zhang, R.; Zhu, Y. A Strategy of Enhancing the Photoactivity of g-C 3 N 4 via Doping of Nonmetal Elements: A First-Principles Study. J. Phys. Chem. C 2012, 116, 23485-23493.

(S8) Lotsch, B. V.; Doblinger, M.; Sehnert, J.; Seyfarth, L.; Senker, J.; Oeckler, O.; Schnick, W. Unmasking Melon by a Complementary Approach Employing Electron Diffraction, SolidState NMR Spectroscopy, and Theoretical Calculations-Structural Characterization of a Carbon Nitride Polymer. Chem. - Eur. J. 2007, 13, 4969-4980.

(S9) Fina, F.; Callear, S. K.; Carins, G. M.; Irvine, J. T. S. Structural Investigation of Graphitic Carbon Nitride via XRD and Neutron Diffraction. Chem. Mater. 2015, 27, 2612-2618. 